\title{
Del autor en la historia del cine. Revisiones y nuevas vías
}

\author{
Egilea zinearen historian. \\ Berrikusteak eta bide berriak
}

\author{
On author in film history. \\ Revisions and new ways
}

\section{José María Galindo Pérez¹}

\section{zer}

Vol. 20 - Núm. 39

ISSN: $1137-1102$

e-ISSN: $1989-631 \mathrm{X}$

DOI: $10.1387 /$ zer. 15517

pp. 49-66

2015

Recibido el 21 de abril de 2014, aceptado el 28 de septiembre de 2015.

\section{Resumen}

Numerosos críticos, teóricos e historiadores se han valido de la noción de autor para armar desde políticas interpretativas hasta sofisticados planteamientos intertextuales. La cuestión que subyace es que el autor cinematográfico, ya sea en su variante física, ya en su dimensión textual, es el productor de un texto fílmico, el origen de un producto acabado. Ese resultado final ha fijado una sólida idea: el autor cinematográfico lo es en función de las películas que realiza. El presente trabajo tiene como objetivo poner al descubierto otra vía de entrada para el análisis del concepto de autor cinematográfico: el proceso cinematográfico.

Palabras clave: Autor, texto fílmico, proceso cinematográfico, análisis textual, política de autores, historia del cine.

\section{Laburpena}

Kritiko, teoriko eta historialari askok 'egile' nozioa erabili dute hainbat azalpenetarako, politika interpretatiboetatik planteamendu intertestual sofistikatuetara. Horren azpian dagoen kontua zinegilea da testu filmikoaren produktorea dela, produktu amaituaren jatorria dela, bai aldaera fisikoan zein testualean. Azken emaitza horrek ideia sendoa finkatu du: zinegilea bada egiten dituen filmen arabera. Lan honen helburua da zinegilearen kontzeptua aztertzeko beste bide bat agerian uztea: prozesu zinematografikoa.

\footnotetext{
Universidad Rey Juan Carlos, josemg87@gmail.com
} 
Gako-hitzak: Egilea, testu filmikoa, prozesu zinematografikoa, azterketa testuala, egileen politika, zinearen historia.

\begin{abstract}
So many film critics, film scholars and film historians have taken the concept of author to built some of their proposals, like an interpretative politics or sophisticated textual approaches. The matter which underlies is the next one: the author in cinema, thought as a person or as a textual strategy, makes a film, and that film is finished work. This idea has become the touchstone for any approach to this topic: someone is a film author depending on the films that he makes. The goal is discover another way to review the concept of author in cinema: the filmmaking.

Keywords: Author, filmic text, filmmaking process, textual analysis, author politics, film history.
\end{abstract}




\title{
1. La centralidad del autor en el mundo del cine
}

En su célebre diatriba contra la figura del autor, Roland Barthes escribió lo siguiente:

\begin{abstract}
"Aún impera el autor en los manuales de historia literaria, las biografías de escritores, las entrevistas de revista, y hasta en la misma conciencia de los literatos, que tienen buen cuidado de reunir su persona con su obra gracias a su diario íntimo; la imagen de la literatura que es posible encontrar en la cultura común tiene su centro, tiránicamente, en el autor, su persona, su historia, sus gustos, sus pasiones; la crítica aún consiste, la mayor parte de las veces, en decir que la obra de Baudelaire es el fracaso de Baudelaire como hombre; la de Van Gogh, su locura; la de Tchaikovsky, su vicio: la explicación de la obra se busca siempre en el que la ha producido, como si, a través de la alegoría más o menos transparente de la acción, fuera, en definitiva, siempre, la voz de una sola y misma persona, el autor, la que estaría entregando sus 'confidencias"” (Barthes, 1987: 66).
\end{abstract}

A pesar de nombrar a Van Gogh o a Tchaikovsky, la crítica de Barthes centraba su atención en el mundo de la literatura. En ese acercamiento, hace una certera relación de los elementos del campo cultural literario donde el concepto de autor se manifiesta más claramente como noción rectora. A saber: en el ámbito de lo editorial (biografías de escritores, publicación de diarios), en el mundo de lo académico (manuales de historia literaria, la interpretación en base a lo dicho del texto por su productor), en el mundo de lo periodístico (las entrevistas como contenido estrella de las cabeceras, la crítica literaria y su culto personalista).

Es innegable la importancia que este concepto -que no es ni más ni menos que una construcción ideológica y sociocultural- tiene en el campo literario. Ahora bien, pensando en las concomitancias de ese campo con el que interesa a este trabajo, el campo cinematográfico, cabría preguntarse en qué sentido pueden trasladarse las observaciones de Barthes al mundo del cine. De esta manera, se puede apreciar lo siguiente:

a) Gran parte de la producción historiográfica sobre cine pivota sobre lo que Alonso denomina los "grandes jalones" (Alonso, 2000: 27), haciendo referencia a categorías como "obras, autores, estrellas, estudios, géneros, estilos". No hace falta señalar que el término que importa a este artículo se sitúa en una posición destacada en esa lista sobre los conceptos vertebradores en los estudios sobre cine.

b) Derivado directamente de lo anterior hay que mencionar las numerosas monografías sobre personalidades del cine. Por supuesto, estas personalidades responden a la descripción tácitamente asumida de autor cinematográfico. Resulta de interés aventurar algunas ideas sobre una colección tan asentada editorial y académicamente como la de Cineastas 
de Ediciones Cátedra. Titulada significativamente 'Cineastas', cuando todos los libros de la colección están dedicados al análisis de directores de cine. Y, por consiguiente, directores de cine que, de una u otra manera, responden a la escurridiza vitola de autores cinematográficos. ¿Acaso los productores, guionistas, intérpretes, músicos, montadores, fotógrafos, decoradores o sonidistas son menos cineastas? ${ }^{2}$

c) En el ámbito de la información y de la crítica cinematográfica ${ }^{3}$ el concepto de autor sigue siendo vertebrador. Por supuesto que existen diferencias entre unas publicaciones y otras -conviviendo en el mercado desde las propuestas más cercanas a la inmediatez de los estrenos y el atractivo de las estrellas hasta las cabeceras de carácter más erudito y analítico-, pero es innegable la importancia de la figura del director como autor a la hora de cuestiones como el número de páginas reservadas, la atención dirigida a las películas o la importancia de las entrevistas -y el contenido de las preguntas, ya que sigue muy presente la idea del autor como principal autoridad interpretativa sobre su obra-.

La analogía entre mundo literario y mundo del cine a raíz de lo expuesto por Barthes podría extenderse, pero con lo descrito hasta aquí parece claro que el concepto de autor, tantas veces matizado, corregido, criticado o vilipendiado, sigue teniendo un peso específico rastreable en el campo cultural cinematográfico. Ese peso resulta tan intangible que podría asociarse incluso al concepto de aura que Walter Benjamin acuñó para explicar un estatuto concreto de las obras de arte basado en su contemplación en el aquí y ahora. Y ese peso se funda sobre una serie de mitos entre los cuales la dicotomía entre el Autor y el Artesano ${ }^{4}$ mantiene su vigencia aun hoy en día.

No es el objetivo de este trabajo el discutir, una vez más, todo el edificio teórico -y en ocasiones hasta esotérico- que subyace bajo el concepto de autor. La pretensión es otra muy distinta, y parte de la asunción de que la noción de autor cinematográfico, independientemente de las filias y las fobias de analistas y estudiosos, existe y no parece que vaya a desaparecer próximamente. Aceptado esto, el siguiente paso es, por lo tanto, indagar nuevas funcionalidades para esa categoría a la luz de las características que exhibe actualmente el mundo del cine en todas sus dimensiones -desde la producción de imágenes y filmes, hasta la recepción y fruición de los mismos, pasando por las diferentes estrategias de interpretación y las convenciones socioculturales e ideológicas construidas y asumidas o rechazadas-. En otras palabras, no se trata de posicionarse a favor o en contra del concepto de autor, sino de rastrear y, en la medida de lo posible, obtener, una nueva operatividad que dote de sentido al término.

2 Esta pregunta no es obstáculo para seguir considerando la labor del director de cine como crucial, en tanto en cuanto ha de resolver la decisiva tensión entre la puesta en escena y la puesta en cuadro. Esta cuestión es discutida en un artículo reseñado en la bibliografía final (Alonso, 2013).

3 Al término de crítica se le da una acepción periodística/editorial, alejada de otros sentidos más inclusivos que tienden a englobar junto a la crítica en los medios la llevada a cabo en el seno del mundo académico.

4 A pesar de que una propuesta como la de Sennett (2008) muestra lo diluidas que están las barreras entre ambos términos, y que las disensiones entre uno y otro son, lisa y llanamente, ideológicas. 
El itinerario propuesto por el presente artículo es el siguiente: examinar y clasificar las vías de entrada al concepto de autor -ya sea desde la crítica de cine, desde la filosofía, la teoría literaria o los estudios fílmicos- a partir de un criterio teórico que elude lo cronológico; identificar el sesgo común a todas las propuestas, muy íntimo a pesar de las profundas divergencias entre unas y otras; $y$, finalmente, plantear una alternativa viable que abra nuevas líneas de investigación que impriman una nueva utilidad metodológica a esa expresión tan densa y a la vez tan vaciada: el autor cinematográfico.

\section{Taxonomía de los acercamientos al concepto de autor cinematográfico}

Eludiendo una panorámica lineal acerca del debate sobre la figura del autor en cine , $^{5}$ este trabajo pretende esbozar una tipología de las propuestas críticas y teóricas sobre la figura del autor cinematográfico en base a un criterio distinto. Fundamentalmente, la idea rectora es la consideración del autor desde su individualidad personal o bien desde su textualidad. En otras palabras, las teorías y propuestas serán clasificadas en función de si en la problemática del autor este prevalece como persona física productora de una obra o como elemento textual configurado por ese entramado de significados y significantes que es la obra.

En aras de la sencillez expositiva y de la concisión interpretativa, se proponen cuatro grandes categorías en las que encuadrar todos los acercamientos a esta cuestión. Huelga decir que esta propuesta es (debe ser) discutida y refinada por reflexiones y análisis posteriores.

La primera gran categoría puede denominarse la de la fidelidad incondicional. Referencia ineludible en este sentido los redactores de la revista Cahiers du cinèma, los François Truffaut, Jean-Luc Godard, Jacques Rivette, Eric Rohmer o Claude Chabrol que posteriormente pasarían de la crítica a la dirección. Los términos son lo suficientemente claros, así que bastará con señalar que las ideas lanzadas por esta política ponen la personalidad del responsable del filme por encima de todo, incluida la propia película. Esa personalidad, por lo tanto, puede ser identificada y rastreada en todas y cada una de sus películas en forma de tópicos temáticos, motivos formales o recursos estilísticos. Lo relevante en los filmes son las huellas que permiten señalarlas como testimonios de una visión, de una personalidad individual. Esta postura antropocéntrica de la política de los autores cahierista, en la que el hombre, el autor, lo condiciona y lo cataliza todo, será seguida por el crítico estadounidense Andrew Sarris.

Sarris -quien, no obstante, fluctuó y matizó su postura en este debate en varias ocasiones- propone un acercamiento a la historia del cine basado en la figura del director y de sus películas. Ahora bien, en esta dicotomía conceptual director/película deja bien claro su punto de vista cuando afirma que "el director fuerte impone su personalidad a la película, en tanto que el débil permite que las personalidades de los demás queden grabadas en ellas" (Sarris, 1970: 30). Es decir, que, a pesar de todas las refinaciones y ajustes que Sarris pretenda llevar a cabo sobre las propuestas críticas de los cahieristas, el hecho diferencial sigue siendo la persona que dirige, su peculiar carácter y la forma en que su personalidad se impregna en la película de la que es responsable.

5 Un buen repaso de estas características puede encontrarse en Cuevas Álvarez (1994). 
Dentro de esta fidelidad incondicional, cabe mencionar también las tesis que los ideólogos de los cines latinoamericanos desarrollaron (Casetti, 1994: 96-100; Stam, 2001: 115-129). En dichas propuestas, la figura del autor continúa siendo central y fundamental a la hora de valorar y analizar una película. El cambio es la forma en que ese autor se manifiesta en su obra: mientras que la política de autores de Truffaut y compañía o la teoría de autor de Sarris aludía a la personalidad individual como fundamento del estilo del filme, la tradición teórica latinoamericana indica que ese estilo autoral se vincula a cuestiones nacionales y a una motivación basada en el cambio social.

Esta categoría de la fidelidad incondicional es la más marcada por el carácter programático, político y polemista de las propuestas que la constituyen. De hecho, ninguna de ellas debe ser entendida como una teoría articulada, ni siquiera lo pretenden. Un ánimo de reivindicación -ya sea de una forma de entender el cine y su realización, de una cinematografía concreta o de una voluntad social de los cineastas- que es el verdadero motor de las ideas y opiniones vertidas en este ámbito. Su escaso rigor y su búsqueda constante de controversia han hecho de estas propuestas una diana constante de críticas y correcciones.

La segunda gran categoría, directamente vinculada a la primera, es la de la aceptación matizada. Una categoría que puede ser personificada por dos ejemplos sumamente distantes entre sí, pero paradójicamente próximos en sus ideas sobre el autor cinematográfico. Se trata de André Bazin, figura de referencia para los críticos de Cahiers du cinèma pero, irónicamente, distanciado del furor autoral del que sus pupilos hacen gala en sus textos, y de Peter Wollen, representante del mundo académico, como acredita su intención de acercar el concepto de autor en cine a postulados estructuralistas y semióticos.

¿En qué consiste esa aceptación matizada? En la convivencia de los siguientes elementos: por un lado, la pervivencia de una jerarquía en los creadores audiovisuales, pirámide valorativa; por otro lado, la puesta en valor del concepto de obra, completamente arrinconado por los seguidores más radicales de la política de los autores, y que, a juicio de los analistas ubicados en esta categoría, merece una atención que no debe ser eclipsada por la omnímoda personalidad del autor cinematográfico.

Bazin, en un texto ya clásico de Cahiers du cinèma, señalaba claramente su postura en el debate sobre esta figura (en De Baecque, comp., 2003: 91-105). Rechazando las peligrosas derivas a las que se expone la política de los autores de usarse de manera abusiva -a saber, el ya célebre "culto estético a la personalidad" y el riesgo a rechazar o ignorar películas por el hecho de no estar dirigidas por un autor-, Bazin propone dos matizaciones notables para contribuir a la revitalización y, en última instancia, protección de una idea sobre el cine con la que afirma estar de acuerdo dada su rentabilidad crítica.

Dichas matizaciones son la consideración de los factores históricos, sociales, económicos y culturales que condicionan la praxis fílmica de cualquier director de cine -incluidos los autores-, y la revalorización de la obra a la hora de enfrentarse al análisis de una película -tratando de evitar el desprecio a piezas estéticamente dignas por el hecho de no estar sometidas al régimen del autor-. Ambos ajustes indican, en el fondo, una necesidad: la de rebajar el peso del autor como criterio interpretativo a priori, otorgando más importancia a dos elementos muchas veces puestos en contradicción hermenéutica, el texto y el contexto. 
Por su parte, Peter Wollen, operando en un ámbito diferente al de Bazin, muestra significativas concordancias en su acercamiento a la figura del autor cinematográfico. Deja claro su afecto al concepto cuando distingue entre auteur y metteur en scène, atribuyendo al primero un trabajo en los ámbitos de la semántica -los temas y los significados- y de la estética -las formas-, y reservando para el segundo una simple función de traductor de un material ya existente a lenguaje audiovisual. Según Wollen, si la teoría del autor ha sobrevivido -a pesar de los múltiples deslices cometidos en su nombre- se debe a que resulta indispensable para la labor crítica (Wollen, 1972: 74-115).

El problema surge cuando quiere reconciliar el acercamiento estructural que propone con la figura del autor. El acercamiento estructural pretende poner de manifiesto los rasgos temáticos y estilísticos de una película singular, lo que, en principio, desbarataría los rasgos generales de la política de autores -basada en el rastreo de marcas personales a la lo largo de toda una trayectoria fílmica-. Wollen propone entonces integrar los acercamientos estructurales singulares en un análisis global de la obra de cada autor, imponiéndose de ese modo un estudio basado en la tensión universalidad/singularidad -observando cómo una película funciona siguiendo las características propias de la filmografía de su autor, y cómo una película se enfrenta a unas variaciones de los temas y motivos de la filmografía completa-.

Por si no fuera suficiente, Wollen plantea una dicotomía más, esta vez completamente centrada en un detalle capital del autor: su nombre. En este caso, el estudioso sugiere distinguir entre el nombre que designa a la persona física -por ejemplo, John Ford- de la etiqueta textual que aglutine una serie de características estructurales compartidas por varios filmes -por ejemplo, la estructura "John Ford"-. Con el uso de esas comillas, Wollen señala claramente el límite decisivo entre la persona física y la estrategia textual, esa cesura que este trabajo ha elegido como criterio clasificador - a pesar de que el propio Wollen pretende mantener un pie en cada hemistiquio, con la consabida precariedad teórica que de ello se deriva-.

En resumen, ya sea con las atinadas correcciones de Bazin o con las sugestivas pero un tanto alambicadas propuestas de Wollen -en caso de disponer de más espacio podrían comentarse también otras aportaciones como las de Geoffrey NowellSmith, Alan Lovell o Ben Brewster- lo que está claro es que la utilidad de la primera categoría se reduce a la polémica crítica, al lanzamiento del debate. En cuanto la discusión se refina y los argumentos se sofistican, es necesaria una complejidad metodológica también. En el acto de congeniar un aparato metodológico más armado con el reconocimiento de la superioridad estética del autor cinematográfico es donde encuentra su lugar esta segunda categoría.

La tercera gran categoría es la del traslado del autor físico al autor discursivo. Es evidente que la cuestión alcanza aquí un debate que trasciende los límites de la discusión sobre el autor cinematográfico, situándose en el centro de una controversia que ubica al texto como el concepto rector, desplazando al autor a un lugar no central y que ha de ser discutido. El autor deja de ser una personalidad física fuerte y presente para asumir un estatuto derivado directamente de su relación con el texto a interpretar y con el contexto que recibe ese texto. Un número muy elevado de estudiosos y teóricos podrían ser invocados en este apartado, pero, por la singularidad o el peso específico de sus propuestas y sus aparentemente distantes linajes intelectuales y 
metodológicos, este trabajo centrará su atención en Michel Foucault, Umberto Eco, Harold Bloom y Wayne C. Booth.

La aportación de Foucault a este debate reside en el concepto de la función-autor. Tras unos apuntes sobre las dos nociones que, según él, obstruyen la desaparición/ disolución del autor - a saber, la obra y la escritura-, describe las características de esa función-autor, que, resumiendo, podrían agruparse así: a) su dependencia de las reglas y normas que rigen el universo de los discursos; b) su dependencia del tiempo y el espacio en el que se ejerce; c) su naturaleza de resultado de una serie de operaciones culturales complejas -rechazando la espontánea atribución de un discurso a su productor-; y d) su carácter de reunión de múltiples egos, de agrupación simultánea de varias posiciones-sujeto ocupadas por diferentes clases de individuos.

La función-autor es un hallazgo de primer orden en la discusión intelectual que este trabajo está perfilando, pues desplaza claramente la noción de autor desde lo que Foucault llama el productor del discurso hasta la relación estratégica entre el texto y su contexto. Examinando diversas cuestiones como el plagio, el anonimato o los criterios de la crítica literaria a la luz de esa función-autor, el pensador francés revela multitud de aristas que, centrando el foco en ese productor del discurso, ni siquiera serían tenidas en cuenta ${ }^{6}$. Y lo hace aboliendo cualquier tipo de frontera que se le pudiera atribuir al concepto de autor: Foucault no teoriza sobre el autor literario, sino que posibilita que su acercamiento al autor se pueda usar a la hora de analizar cualquier tipo de discurso -lo que, en el caso que nos ocupa, que no es otro que el autor cinematográfico, es ciertamente muy útil-.

Las propuestas de Eco y de Booth tienen un sesgo similar. Ambos se afanan en desgajar de la persona física -a quien el primero denomina como autor empírico y el segundo como autor real- una versión textual construida por el lector/intérprete en su enfrentamiento directo con el texto. Una construcción, además, validada por las posibilidades hermenéuticas que proporciona el texto, impidiendo de esa manera lecturas que transgreden esa economía interpretativa abanderada por el semiólogo italiano.

Eco llama a esa versión textual el autor modelo, mientras que Booth la nombra como el autor implícito. En cualquier caso, y más allá de las diferentes nomenclaturas, la idea central es parecida: el orden del discurso no está aparejado, ni mucho menos subordinado, al orden del individuo físico. La política de los autores vería en este punto una refutación drástica a esa preeminencia estética de la personalidad individual que se halla en el núcleo de su actividad crítica. Tal y como señala Eco (2013: 155), un texto no se interpreta según las intenciones del autor empírico, sino "según una compleja estrategia de interacciones que implica también a los lectores, junto a su competencia de la lengua como patrimonio social", entendiendo ese último concepto -la competencia de la lengua como patrimonio social- como un conjunto de elementos que incluye normas gramaticales, convenciones socioculturales producidas por esa lengua y la trayectoria de textos interpretativos previos, entre otros. Por su parte, Booth cerca

\footnotetext{
${ }_{6}$ Significativa en este sentido es la vinculación existente entre el esquema interpretativo de los críticos literarios para señalar a un autor y los criterios de los exégetas cristianos para determinar la validez de los textos de los que disponían para conformar el canon dogmático. Ambos campos, separados considerablemente en el tiempo y en el espacio, pueden regirse por los parámetros propuestos por San Jerónimo en De viribus illustribus: cierto nivel constante de valor, cierto campo de coherencia conceptual y teórica, cierta unidad estilística y cierta pertinencia sociohistórica.
} 
aún más esa concepción del individuo y su personalidad como criterio estético cuando afirma que el autor real genera versiones implícitas de sí mismo,

"porque sus diferentes obras implicarán diferentes versiones, diferentes combinaciones ideales de normas. Igual que las cartas personales de uno implican diferentes versiones de uno mismo, según las diferentes relaciones con cada corresponsal y el propósito de cada carta, de la misma manera el escritor se presenta con un aire distinto dependiendo de las necesidades de obras específicas" (Booth, 1974: 71).

Recapitulando, las ideas de Eco y Booth apuntan a que la instancia decisiva para la crítica y la interpretación no es el autor físico - ese productor del discurso al que se refería Foucault- sino el texto en sí. La personalidad del autor es sustituida por un concepto del autor como estrategia textual que opera según las indicaciones que proporciona el propio texto. Sin embargo, a pesar de la relación de los puntos de vista de ambos, no hay que perder de vista las diferencias que impiden equiparar completamente ambas teorías. Booth, moviéndose en el ámbito de la crítica literaria, desdobla la figura del autor en sus variantes explícita e implícita para analizar el papel de los elementos retóricos de la persuasión en la narración construida para el lector. Eco, en cambio, articula su concepto como complemento necesario del lector modelo: una instancia textual que se relaciona íntimamente con el autor modelo para la interpretación del texto. En otras palabras: si en Booth el texto es el espacio de significación donde el autor persuade estilísticamente al lector, en Eco el peso de la pragmática es tan grande como para que el sentido del texto se construya en la relación de las dos entidades textuales modelo.

En cuanto a Harold Bloom, sus ideas acerca del autor pueden hacer que su inclusión en esta tercera gran categoría sea vista como incoherente. Cuando realiza afirmaciones como "la historia poética [...] sería indistinguible de la influencia poética, pues los poetas fuertes forjan esa historia malinterpretándose unos a otros para despejar un espacio imaginativo para sí mismos" (Bloom, 2009: 55), o "la influencia poética, cuando afecta a dos poetas fuertes, auténticos, tiene lugar siempre por una malinterpretación del poeta anterior, un acto de corrección creativa que es, real y necesariamente, un malentendido" (Bloom, 2009: 78), parece dejar claro que sus posturas se acercan mucho a la reivindicación de las personalidades estéticas de los escritores. Por no mencionar el hecho de cómo organiza Bloom sus respectivos libros, siempre a modo de listas de novelistas, poetas o ensayistas, dejando claro que, aparentemente, el autor es la figura central de la literatura.

Sin embargo, lo que Bloom desarrolla con esa idea de la contaminación e influencia entre autores no es ni más ni menos que una teoría intertextual de la literatura, en la que, en última instancia, los elementos que vehiculan esa red de influencias son los propios textos. No es Shakespeare - por usar el emblema de las teorías de Bloom- quien condiciona e influye en Milton o Tolstoi, por ejemplo, sino que son los textos de Shakespeare los que perfilan el modo de existir y descifrar de los textos de Milton o Tolstoi. 
Aunque podría parecer realmente significativo que uno de los grandes valedores de la figura del autor en la literatura sea, finalmente, el responsable de una teoría centrada en el escrutinio de los textos, esa paradoja no es tal. Su defensa acerada del placer estético proporcionado por el texto literario es un claro reclamo a favor de la lectura estética de los textos, de una lectura de la forma literaria. Y la metodología más propicia para aprehender esa forma y sus mecanismos de funcionamiento es el análisis de los textos, más allá de biografismos esotéricos o de interpretaciones impresionistas e impertinentemente personalistas. Por lo tanto, la lucha por el placer estético parece que, en última instancia, está vinculada al acercamiento riguroso al texto. Parece que, después de todo y en un aspecto bastante particular, Bloom no se aleja tanto de Eco.

Después de todo lo expuesto, puede afirmarse que esta tercera gran categoría se caracteriza fundamentalmente por situar el concepto de texto en lo más alto de las prioridades interpretativas, siendo el autor una noción problemática que acaba por descorporeizarse para asumir un rol textual diferenciado de su existencia física como individuo creador/productor de una obra o discurso determinado.

Finalmente, la cuarta gran categoría sería la de la negación absoluta. Una categoría que puede ser vinculada directamente con Roland Barthes, y que establece una relación muy particular con esa fidelidad incondicional con la que se abría esta taxonomía. Pues, a pesar de que son los polos opuestos de un espectro, están imbuidos por un similar ánimo polemista -contando con que los críticos de Cahiers y Barthes operan desde un instrumental analítico y en unos campos culturales diferentes- y representan una postura extrema en el debate sobre la figura del autor.

No en vano, el título del artículo de Barthes que centraliza esta categoría es ni más ni menos que "La muerte del autor". Y en él se hallan puntos de vista nodales para esta cuestión ilustrados por expresiones como "la escritura es la destrucción de toda voz, de todo origen", negando de esa manera cualquier tipo de autoridad, "el texto es un tejido de citas provenientes de los mil focos de la cultura", atribuyendo la responsabilidad del sentido del texto al diccionario de textos que paga con la muerte del autor" (Barthes, 1987: 65, 69, 71), señalando al lector como el espacio donde se congregan la multitud de textos cuyos ecos resuenan en cada escritura, y rechazando al autor como principio vertebrador de la interpretación y el estudio de los textos.

En definitiva, Barthes plantea un modelo en el que el texto como caja de resonancia de otros textos y discursos de la cultura, y el lector como instancia donde se traza el sentido de ese tejido intertextual, actúan como ejes de una situación en la que el autor queda, finalmente, evacuado. La pregnancia de esa propuesta es tal que las nociones de texto y lector no deben suponer alusiones al campo literario, sino al conjunto de formas expresivas y discursivas que una comunidad cultural sea capaz de señalar. Y esto incluye, como no podía ser de otra manera, al campo cinematográfico.

\section{El problema nuclear}

El propósito que persigue la propuesta de clasificación anterior es doble. Por un lado, pretende esbozar un panorama de los planteamientos más significativos en el análisis de la figura del autor y, más concretamente, del autor cinematográfico. Por otro lado, indicar una característica común a todos esos acercamientos, a pesar de 
todas sus divergencias, y que es la clave para dar paso a un nuevo tipo de reflexión sobre este concepto.

Eso que hemos dado en llamar el problema nuclear puede ser introducido a través de los argumentos de Cristina Pujol Ozonas:

"Thomas Elsaesser plantea que la ruptura que suele marcarse en los estudios de cine entre los años de la cinefilia y la teoría del autor (1950-60) y las décadas del giro estructuralista-semiótico (1960-70) no es tal: en lugar de plantear que los análisis textuales surgieron contra un exceso de cinefilia de la teoría del autor, Elsaesser propone que las deconstrucciones semióticas fueron precisamente una vía de escape frente al desencanto que supuso el fin de la cinefilia" (Pujol Ozonas, 2011: 59).

El párrafo previo merece unos comentarios. Este trabajo no comparte esa línea teleológica que según Pujol Ozonas une a la teoría del autor con los planteamientos estructuralistas. No deben ser considerados como elementos de una relación causaefecto, ya que, como se indicó previamente a colación de las puntuales concomitancias habidas entre la política de Cahiers y las ideas de Barthes, ni las herramientas metodológicas ni los campos de actuación son del mismo orden. Por ello, se antoja inadecuado trazar esa presunta evolución.

Dicho lo cual, relacionar -aunque sea de manera tan forzada- la política de los autores y el estructuralismo -las dos puntas de lanza de la tipología de análisis propuesta más arriba- tiene una ventaja: poner de manifiesto que, a pesar de todo, hay un vínculo entre todas las posturas interpretativas que se han acercado al autor (cinematográfico).

Ese vínculo es la preponderancia del texto como lugar del análisis. Pero hay que precisar: no se trata, en este caso, del texto como concepto que pueda oponerse bien al contexto, bien al autor. El texto, en este caso, ha de entenderse como un producto, un resultado, que en este caso es fácilmente identificable: la película. Ya sean los incondicionales del autor como personalidad estética, sus moderados seguidores, los estudiosos que escinden el mundo físico del mundo del discurso explorando en ambos esta problemática o un Roland Barthes que ataca frontalmente, el espacio donde poner a prueba las especulaciones, los razonamientos, las ideas y las afirmaciones siempre es la película, la obra acabada, la pieza cerrada.

La personalidad estética de Fritz Lang cuya existencia afirman los críticos de Cahiers du cinèma ha de ser rastreada en las películas atribuidas a Lang. Las estructuras de Wollen y compañía nacen del análisis riguroso de las películas cuya autoría se atribuye a un director u otro. El propio Bazin pone en valor la obra -es decir, la película- para frenar ciertos desmanes personalistas. Eco o Booth distinguen entre autor empírico/autor real y autor modelo/autor implícito, pero los mecanismos textuales que perfilan al segundo hay que buscarlos en el texto -en este caso, en las películas-. Y cuando Barthes levanta la voz contra el autor, lo hace describiendo el texto como red de citas intertextuales. Es decir, el texto, el resultado final, la película, es el lugar donde validar ya sea la tarea crítica, ya sea la investigación teórica. 
Conviene hacer aquí un comentario: es absolutamente lógico y pertinente contrastar en las películas, en "la materialidad de la forma fílmica" (Zumalde, 2006), las conclusiones de la labor interpretativa de un crítico, un historiador, un teórico, un analista. Someterse a las reglas que dicta el texto fílmico suele ser un aval bastante sólido para dotar a las conclusiones obtenidas de sentido común y coherencia.

Tal y como señala José Luis Castro de Paz cuando comenta críticamente un pasaje de la Historia del cine español editada por Cátedra escrito por José Enrique Monterde en el que se aboga por una desviación del foco desde la figura del autor hacia otros aspectos de un nivel más general, "si la figura del autor no resultaba demasiado operativa, quizás hubiese sido más provechoso aproximarse con rigor al auténtico objeto de estudio: las películas" (Castro de Paz, 2002: 30).

El problema, por lo tanto, no es recurrir a la película como texto completado. El problema es, quizá, olvidarse de la condición necesaria para que exista un producto acabado final: un proceso. Y es ahí donde conviene explorar las posibilidades teóricas que plantea el concepto del autor cinematográfico en los estudios de cine en la actualidad.

\section{Las posibilidades del autor cinematográfico como concepto teórico}

Tras numerosos debates y abundantes ríos de tinta, se antoja oportuno explorar qué vías de análisis pueden resultar rentables a la hora de estudiar el concepto de autor cinematográfico. Desde este trabajo se aventurarán tres líneas de investigación generales, lo cual no es óbice para que existan otras o para que las mencionadas aquí puedan ser debatidas o, incluso, recusadas.

La primera de esas líneas viene inspirada por las ideas de Jonathan Culler. Escribiendo sobre la crítica literaria feminista, Culler advierte que las características del autor en una cultura paternalista dan como resultado una visión distorsionada de este, llegando al extremo de considerar al autor como padre -no madre-de sus textos y a la crítica como la entidad guardiana -o figura paternal- de los significados legítimos de las criaturas del autor/padre. Sin entrar a discutir las implicaciones de esta propuesta -ya que su complejidad desborda por completo los límites conceptuales y de espacio del presente trabajo-, el aliento metodológico de Culler señala algo muy interesante: el uso de la figura del autor como motor de la reflexión de conceptos y dinámicas de funcionamiento completamente asumidas y naturalizadas.

No hay que esforzarse demasiado para vislumbrar la importancia que un planteamiento así puede tener para los análisis que caen dentro de los dominios de los Estudios Culturales. Partiendo del autor cinematográfico como una construcción producida en unas coordenadas socioculturales concretas, parece que el abordaje de este concepto sería un útil ariete para teorías de corte feminista, queer, colonial o nacional. Algo de esto ya podía intuirse cuando, en un apartado anterior, las revisiones teóricas de Casetti o Stam diferencian las ideas sobre el autor cinematográfico en Occidente -Europa y Estados Unidos- y en Latinoamérica -siendo esta región un bastión destacado de la reacción geopolítica a la dominación occidentalista-. De la misma manera que una aproximación al autor en cine desde una óptica similar a la adoptada por Laura Mulvey en su ya clásico "Placer visual y cine narrativo" (Wallis, 2001: 365-377) podría poner de manifiesto pautas de funcionamiento y de 
construcción de esa figura que, de momento, no hayan sido puestas de manifiesto. Instituciones legitimadoras, agentes dadores del estatuto de autoría, características psicosociales de los candidatos a autor o la figura del autor cinematográfico en el ámbito de la recepción serían solo algunos de los aspectos que podrían ser sometidos a riguroso examen.

Completamente alejada de la raigambre de esta primera línea aparece la segunda, centrada, una vez más, en el texto fílmico como principal referente para el estudio de la cuestión. Sin embargo, y a pesar de lo señalado anteriormente -a saber, esa constante atención al texto, la película, como producto final que guía los puntos de vista argumentados sobre el autor cinematográfico-, lo cierto es que esta línea de investigación continúa aportando conclusiones interesantes y, lo que puede que sea más importante, conceptos operativos. En este ámbito es ineludible referirse a Imanol Zumalde y sus trabajos sobre este particular, a partir de los cuales se han definido dos maneras de utilizar el concepto de autor cinematográfico, complementarias entre sí.

Por un lado, describe el concepto de autor en cine a partir del escrutinio de cuestiones tales como el repertorio de motivos temáticos y formales, la fidelidad a esos motivos y la regularidad con la que se recurre a esos elementos, para acabar afirmando que "así descrito, dicho concepto [...] es muy parejo al de estilo entendido como conglomerado de temas [...] y figuras [...] puestos en forma [...] con arreglo a unos parámetros estéticos concretos" (Zumalde, 2002: 191). De esta forma Zumalde se acerca a Jean Mitry, cuando afirmaba que "un autor es mucho menos quien imagina una historia que quien le da una forma y un estilo" (Mitry, 2002: 37). La refinación de este argumento evoluciona a través de sus obras sobre el análisis textual y sus diferentes implicaciones teóricas, hasta llegar a la siguiente definición: "un autor cinematográfico es, por regla general [...], aquel cuyas películas alcanzan a interrelacionarse entre sí antes que con películas que llevan otra firma" (Zumalde, 2013: 15).

Lo más valioso de estas aportaciones es, como ya se ha indicado, la operatividad que poseen. El autor cinematográfico, a partir de estos planteamientos, puede ser estudiado y analizado en base a una serie de parámetros más o menos mensurables e identificables, desterrando juicios indiscriminados y combates en pos de un director u otro. Centrando el foco en el catálogo de temas y formas -en su existencia, su uso y su frecuencia, por no hablar de la forma en que se hibridan y mutan- y en la manera en que esos temas y formas conviven intertextualmente -rastreando ecos, citas, reformulaciones, revisiones, permanencias o recurrencias- se encara un horizonte interpretativo amplísimo y muy provechoso.

Esta línea de abordar el concepto de autor pone en cuestión todo el entramado teórico que la política de autores cahierista pretendió armar. El culto a la personalidad impide la valoración del texto fílmico con toda la pertinencia exigible y, además, contribuye a generar un discurso crítico basado en la reivindicación ya no solo de nombres concretos, sino de los propios criterios de apreciación. El acercamiento ejemplificado por Zumalde centra el objeto de análisis y, al mismo tiempo, elimina posibles prejuicios interpretativos. Y lo hace evitando considerar, de entrada, mejor un filme de pretensiones "artísticas" que una película de carácter más comercial. Al reducir la unidad de análisis al texto fílmico concreto, se ponen de manifiesto los mecanismos formales de cada uno de ellos. Esos elementos expresivos han de ser interpretados en relación a otras películas del director en cuestión, 
y en ningún caso pesará el hecho de que el director apueste por un circuito u otro del campo cultural cinematográfico.

La valoración crítica, a su vez, debe ser asumida conscientemente por los analistas. El hecho de que determinadas películas respondan a unos modelos temáticos y estéticos más propicios para proporcionar a su director la vitola de autor debe ser tenido en cuenta. Quizá el desplazamiento del foco del producto al proceso contribuya no solo a abrir nuevas vías de investigación sobre el concepto de autor cinematográfico, sino también a la reelaboración de los discursos críticos.

Ahora bien, los acercamientos descritos a la figura del autor cinematográfico son herederos de esa búsqueda de respuestas en la película, en el resultado final. Y, como ya se ha podido comprobar, ese rasgo metodológico se halla en la mayor parte de las teorizaciones sobre este concepto de autor en el cine. Es hora, por lo tanto, de mirar en el anverso del producto para fijar la atención en el proceso cinematográfico. Y para ello, parece apropiado partir de las propuestas de Luis Alonso al respecto.

En un artículo ya citado que aborda directamente ese proceso cinematográfico redescribe el proceso fílmico a partir de una crítica al tradicional esquema administrativo que pliega lo expresivo a lo económico a partir de una famosa secuencia de pasos - pre-producción, en-producción, pos-producción- que naturaliza ese proceso hasta hacerlo como el único concebible.

En su lugar -o quizá mejor dicho, complementando esa visión-Alonso propone devolver lo expresivo a un primer término en un modelo de dos fases: el diseño y el desarrollo. En el diseño se perfilarían el núcleo temático y la matriz estética del proyecto, y en el desarrollo se trabajarían esos conceptos a través de cuatro capas o puestas -la puesta en guion, la puesta en escena, la puesta en cuadro y la puesta en serie-, en un complejo entramado que requiere de la lectura del artículo citado, puesto que no es menester repetir aquí lo expuesto allí.

En este caso de lo que se trata es de aprovechar ese desplazamiento de la mirada del texto fílmico al proceso fílmico, entendiendo este último como un conjunto de actividades, prácticas y rutinas que determinan, de manera crucial, cómo es el cine y cómo son las películas -e igual de importante, cómo se entiende el cine y cómo se entienden las películas-. Las formas de hacer una película no pueden reducirse a consignas notariales en las que se cumple con un procedimiento estándar neutro, ya que esas formas siempre están determinadas por un sesgo ideológico, sea el que sea. No es igual proponer un esquema de trabajo en el que prime la racionalización económica frente a otro en el que se reivindique la labor creativa. Ninguna de esas dos opciones, por no salirnos de los ejemplos tratados, es natural, sino que supone un constructo más o menos consciente, pero siempre resultado de una suma de voluntades y aceptaciones humanas.

Llegados a este punto conviene no olvidar cuál es el concepto que ha conducido el debate hasta aquí: el autor cinematográfico. La clave del estudio del autor, a día de hoy, radica en el encuentro entre el proceso cinematográfico y el concepto del autor en cine. Porque, si su estatuto no se reduce a una cuestión textual, a un rastreo e interpretación posibilitadas y a la vez validadas por la propia película, las razones de la consideración de un director como autor o no-autor habría que empezar a buscarlas en otro sitio: las formas de hacer esas películas. O, por formularlo con una pregunta: ¿el ser autor cinematográfico puede venir dado por la forma de trabajar, de hacer una película? 
Es entonces cuando se impone ordenar en la medida de lo posible esta línea de investigación: en primer lugar, tendría que realizarse una descripción del proceso cinematográfico a través del trabajo de campo de numerosos analistas, partiendo de unas pretensiones ideológicas y un instrumental metodológico que fuera más allá del hacer coincidir lo observado con la pregnante propuesta de las tres fases sucesivas; en segundo lugar, sería esperable una interpretación de esa descripción en función de diversos criterios que condicionan el proyecto cinematográfico - desde el presupuesto manejado hasta el cariz comercial o no de la película, pasando por el tipo de financiación, el trabajo en los distintos géneros o el perfil de los profesionales inmersos en el proyecto-, ajustando esos parámetros lo máximo posible; y, en tercer lugar, se antojaría muy fructífero un análisis comparado de todos esos acercamientos con el fin de dilucidar, en la medida de lo posible, si el trabajo de los cineastas se mantiene incólume a los avatares y los condicionantes que lo rodean.

Recuperando el artículo de Alonso mencionado, en él se hace referencia a un trabajo de campo más o menos articulado alrededor de un proyecto de Jaime Rosales. La figura de Rosales, sin ir más lejos, está completamente tamizada por su inclusión decidida por parte de crítica y de público en esa difusa y etérea categoría que es el cine de autor. Sería, por lo tanto, de enorme interés tener la posibilidad de acceder a un análisis del trabajo de Rosales como director de cine cuando está tan marcado por su condición socioculturalmente atribuida de autor cinematográfico. Y resultaría de aun más interés el poder comparar ese análisis con el de otra figura plenamente marcada por otro rasgo o etiqueta, en este caso el del cine comercial, como es Santiago Segura, por poner un ejemplo comprensible.

Las preguntas pueden parecer baladíes, pero, ¿trabajan de la misma forma Jaime Rosales y Santiago Segura? Por decirlo con otras palabras, ¿trabaja igual un director caracterizado por la preeminencia de los factores expresivos y creativos de su trabajo que un director que acomete su oficio desde las perspectivas de la competencia técnica y la rentabilidad económica? Solo el trabajo de campo y el análisis comparado pueden permitir obtener una respuesta. Y sea cual sea esa respuesta, el trabajo habrá merecido la pena: si resulta que desempeñan su tarea de la misma manera, es evidente que el concepto de autor cinematográfico queda reducido a otras esferas; si las diferencias existen, se abre en ese caso un fecundo y atractivo campo de estudio que puede acabar trasladando un enorme foco de interés al proceso de creación de la película. En cualquier caso, la rentabilidad en términos de conocimiento hace que la empresa merezca la pena.

Antes de concluir, resulta muy oportuno considerar, aunque sea de manera preliminar, algunas de las implicaciones de un posible trabajo de campo analizando el proceso de un proyecto cinematográfico concreto. Un estudio de clara raigambre antropológica, en la que un observador ajeno percibe y registra los detalles del día a día de un determinado colectivo. En este caso, la observación se centraría en un proyecto fílmico y, concretamente, en la figura del director de cine.

Resulta completamente pertinente asomarse a esta posibilidad, pues apenas existen fuentes de información de los directores (y del resto de oficios cinematográficos) más allá de las descripciones y manuales técnicos, de alguna que otra poética de autor más o menos atractiva y de las entrevistas a los propios cineastas. La opción, por lo tanto, de introducir en el proceso a un observador, ajeno a la profesión, pero inicia- 
do en el lenguaje audiovisual y la técnica cinematográfica, se antoja potencialmente muy fructífera. Conviene apuntar que una parte fundamental de esa investigación de campo debería ser las conversaciones con los miembros del equipo, para poder poner en contraste los discursos con las prácticas, supliendo así una de las grandes lagunas de la entrevista como metodología para obtener información.

Ese observador ajeno pero no ignorante presenta, a su vez, la capacidad de la sorpresa y la atención constante. Numerosos detalles que la rutina oculta al profesional sí despertarán la curiosidad del analista no tan familiarizado con ellos. Y la interpretación posterior de todos esos factores puede poner de manifiesto, entre otras muchas cosas, los rasgos del oficio que puedan hacer el concepto de autor operativo en el ámbito de la creación, no solo en el de lo creado.

\section{Apuntes finales}

Llegados a este punto, el de las previsibles conclusiones, parece interesante reducir la glosa de todas las ideas que se han ido poniendo en liza, pues la pretensión ha de ser una bien definida: identificar el contrapeso analítico que propone este artículo. Todo el recorrido del presente trabajo se ha articulado para tratar de poner de manifiesto una nueva veta a la hora de estudiar un concepto tan controvertido y central en la historiografía, la crítica y la teoría del cine como es el de autor cinematográfico.

La clasificación propuesta para categorizar, aparte de la labor taxonómica que se le presupone a toda tipología, tiene por objetivo señalar la preeminencia del texto fílmico a la hora de diseñar y ejecutar cualquier abordaje a la figura del autor en cine. Y, señalado ese punto, la finalidad de este artículo es, en última instancia, proponer la vía del proceso cinematográfico como alternativa viable y productiva para nuevas indagaciones y hallazgos alrededor de la escurridiza noción que aquí se debate.

Dicho lo cual, merece la pena hacer unas pocas precisiones. El plantear la posibilidad, e incluso la pertinencia, de dirigir la mirada analítica hacia el proceso no significa, ni mucho menos, una postura de enfrentamiento hacia los puntos de vista que reclaman la atención para el texto fílmico como resultado final. De hecho, el ánimo que guía lo expuesto anteriormente no es de confrontación, sino de colaboración. Resultan evidentes las enjundiosas conclusiones alcanzadas por acercamientos de ascendencia estructuralista, y sería muy necio querer pleitear contra una metodología de análisis que ha demostrado su validez en numerosas ocasiones.

La cuestión es conseguir una profundidad descriptiva e interpretativa del mismo calado en el ámbito del proceso. Un ámbito que, lamentablemente, está trufado de ideas preconcebidas y de lugares comunes que lastran cualquier posibilidad de lograr un conocimiento útil en este campo. Quién sabe los rendimientos que un análisis del proceso puede producir. Y, yendo más allá, qué podría obtenerse de una comparación entre el análisis de un texto fílmico y el análisis del proceso por el que ha sido producido, en este caso con la figura del autor cinematográfico como vector de la labor hermenéutica.

Para finalizar, la constatación de un hecho: la pobreza metodológica que acusa el análisis del proceso cinematográfico. Una pobreza que se orienta no tanto hacia la escasez de recursos -múltiples herramientas y disciplinas pueden ser invocadas para el desempeño de esta tarea-, sino a la precaria articulación de los mismos. Se impone un engranaje teórico que coordine las distintas aportaciones posibles -sin ánimo de 
exhaustividad: la psicología de la creatividad, la teoría del proyecto artístico, la filosofía de la praxis o la sociología de las técnicas, entre otras muchas potenciales- que permita un aprovechamiento del trabajo de campo.

El autor cinematográfico, en cualquier caso, parece situarse como un concepto que seguirá centrando debates y discusiones en el seno de los estudios fílmicos. De la sagacidad y el rigor de las aproximaciones dependerá lo relevante que pueda extraerse de esas tensiones intelectuales.

\section{Referencias bibliográficas}

ALONSO, Luis (2000). El extraño caso de la historia universal del cine. Valencia: Episteme.

ALONSO, Luis (2013). El saber hacer del proceso fílmico: del cineasta al filmólogo. En: Archivos de la filmoteca, $\mathrm{n}^{\circ} 71$, pp. XIX-XXXII.

BARTHES, Roland (1987). El susurro del lenguaje. Barcelona: Paidós.

BENJAMIN, Walter (1989). Discursos interrumpidos I. Filosofía del arte y de la historia. Buenos Aires: Taurus.

BLOOM, Harold (2004). El canon occidental. Barcelona: Anagrama

BLOOM, Harold (2009). La ansiedad de la influencia. Una teoría de la poesía. Madrid: Trotta.

BOOTH, Wayne C. (1974). La retórica de la ficción. Barcelona: Boch.

BREWSTER, Ben (1973). Notes on the Text 'John Ford's Young Mr. Lincoln' by the Editors of Cahiers du Cinéma. En: Screen, vol. 14 (3), pp. 29-43.

CASETTI, Francesco (1994), Teorías del cine. Madrid: Cátedra.

CASTRO DE PAZ, José Luis (2002). Work in progress: algunas notas sobre una década de historiografía y teoría cinematográfica en España. En: Secuencias, n ${ }^{\circ}$ 16, II semestre 2002, pp. 24-32.

CAUGHIE, John (ed.) (1981). Theories of authorship: a reader. London: Routledge and Kegan Paul.

CUEVAS ÁLVAREZ, Efrén (1994). Notas sobre la teoría del autor en ficciones audiovisuales. En: Comunicación y Sociedad, vol. VII, n. 1, <http:// www.unav.es/fcom/comunicacionysociedad/es/articulo.php?art_id=224> $(22 / 12 / 2013)$.

CULLER, Jonathan (1998). Sobre la deconstrucción. Madrid: Cátedra.

DE BAECQUE, Antoine (comp.) (2003). La política de los cineastas. Manifiestos de una generación de cinéfilos. Barcelona: Paidós.

ECO, Umberto (2013). Los límites de la interpretación. Barcelona: Debolsillo.

FOUCAULT, Michel, Entre filosofía y literatura. Barcelona: Paidós.

GUBERN, Román et al (1995). Historia del cine español. Madrid: Cátedra.

LOVELL, Alan (1969). Robin Wood - A Disenting View. En: Screen, vol. 10 (2), pp. 42-55.

MITRY, Jean (2002). Estética y psicología del cine I: las estructuras. Madrid: Siglo XXI.

NOWELL-SMITH, Geoffrey (1968). Luchino Visconti. Garden City: Doubleday. 
PELLEJERO, Eduardo (2012). Política de autores y muerte del hombre: notas para una genealogía de la crítica cinematográfica. En: Sesión No Numerada: Revista de letras y ficción audiovisual, $\mathrm{n}^{\circ} 2$, pp. 29-53.

PUJOL OZONAS, Cristina (2011). Fans, cinéfilos y cinéfagos. Una aproximación a las culturas y los gustos cinematográficos. Barcelona: Editorial UOC.

SARRIS, Andrew (1970). El cine norteamericano. Directores y direcciones 19291968. México: Diana.

SENNETT, Richard (2008). El artesano. Barcelona: Anagrama.

STAM, Robert (2001). Teorías del cine. Una introducción. Barcelona: Paidós.

WALLIS, Brian (ed.) (2001). Arte después de la modernidad. Madrid: Akal.

WOLLEN, Peter (1972). Signs and meaning in the cinema. Bloomington: Indiana University Press.

ZUMALDE, Imanol (2002). El autor y su sombra. En: Zer. Revista de estudios de comunicación, $\mathrm{n}^{\mathrm{o}} 12$, pp. 173-191.

ZUMALDE, Imanol (2006). La materialidad de la forma fílmica. Crítica de la (sin) razón posestrcuturalista. Bilbao: Universidad del País Vasco.

ZUMALDE, Imanol (2013). Formas de mirar(se). Diálogos sin palabras entre Chaplin y Tati, Lewis mediante. Madrid: Biblioteca Nueva. 